\title{
Effect of Health Education based Intervention on Self-care among Systemic Lupus Erythematosus Clients
}

\author{
Doaa Mohamed Sobhy Elsayed", Soha Kamel Mesbah \\ Community Health Nursing, Benha University, Benha, Egypt \\ *Corresponding author: doaa308@yahooo.com
}

\begin{abstract}
Systemic Lupus Erythematosus (SLE) disease and disease-related consequences as well as treatment-related adverse events have a significant negative effect on life expectancy and quality of life of SLE clients. The study aimed to evaluate the effect of health education based intervention on self-care among systemic lupus erythematosus clients. Design: A quasi experimental design was used. Setting: The study was conducted in Rheumatology Outpatients' clinic of Benha Teaching Hospital. Sample: A Convenient sample of systemic lupus erythematosus clients was recruited. There were 60 clients. Tools: I- structured interviewing questionnaire to determine demographic characteristics of SLE clients, disease characteristics. II- Systemic Lupus Erythematosus Assessment Tool to assess client's knowledge about SLE and clients' practices about self-care. III- Lupus Patient Reported Outcomes (lupus PRO). Results: Showed that, the mean age of studied clients was $28.76 \pm 5.98,90 \%$ were female, $40 \%$ had the disease from 1 to $<5$ years. $36.7 \%$ of them had a family history of SLE, $45 \%$ of studied clients had average total knowledge and $0 \%$ had good total knowledge scores regarding SLE disease, only $18.3 \%$ had satisfactory total self-care reported practices score and $16.7 \%$ had moderate total Lupus PRO score pre intervention, while post intervention; good total knowledge scores increased to $95 \%$ and average total knowledge decreased to $5 \%$, satisfactory total self-care reported practices increased to $83.3 \%$ and moderate total Lupus PRO score increased to $65 \%$. Conclusion: This study concluded that there were a significant improvement in studied clients' knowledge, self-care practices and Lupus PRO regarding SLE disease. Recommendations: Establishing patient education programs to improve SLE clients care by written instructions must be available in all rheumatology clinics. Replicate this study for large number of clients and in different settings.
\end{abstract}

Keywords: Systemic Lupus Erythematosus (SLE), self-care, health education based intervention, SLE clients

Cite This Article: Doaa Mohamed Sobhy Elsayed, and Soha Kamel Mesbah, "Effect of Health Education based Intervention on Self-care among Systemic Lupus Erythematosus Clients." American Journal of Nursing Research, vol. 6, no. 3 (2018): 105-112. doi: 10.12691/ajnr-6-3-4.

\section{Introduction}

Systemic Lupus Erythematosus (SLE or lupus) is a significant public health problem. It is a long-term autoimmune disease, in which the immune system attacks normal body tissues as though they were foreign substances, causing inflammation and tissue damage throughout the body. It characterized by periodic flare-ups of severe symptoms affecting any organ resulting in potentially life-threatening complications [1].

The exact cause of lupus is not known. A person who develops lupus probably inherits the risk from one or both parents and then develops the disease when exposed to a trigger. Triggers may include being exposed to sunlight, being ill with an infection, having surgery, or being pregnant [2].

Symptoms of lupus can be caused by inflammation, which can affect the whole or parts of the body, fatigue and weight changes. Other lupus symptoms are damage to a particular organ system, joint pain and stiffness, skin changes, changes in kidney function, the digestive system can be affected by medications used to treat lupus. Also, Lupus can affect lung, heart, nervous system and eye [3].
Inflammation caused by lupus can affect many areas of body, causing many complications including skin (necrosis), hematologic (thrombocytopenia, hemolytic anemia, neutropenia, catastrophic antiphospholipid syndrome, and thrombotic thrombocytopenic purpura), heart (pericardial tamponade, myocarditis), lung (alveolar hemorrhage, pulmonary hypertension), gastrointestinal (vasculitis, pancreatitis), adrenal insufficiency, and neurologic (myelitis) may be encountered [4].

Self-care interventions were defined as interventions that aim to equip clients with skills to actively participate and take responsibility in the care of their disease in order to function optimally through acquiring knowledge and a combination of at least two of the following: stimulation of independent sign/symptom monitoring, medication management, enhancing problem-solving and decision-making skills for medical treatment management, and changing their physical activity, dietary, and/or smoking behavior [5].

Although there is no cure for lupus, a variety of interventions can reduce symptoms, limit damage to vital organs, and reduce the risk of recurrence. These interventions include diet and nutrition as most people with lupus should eat a well-balanced diet. However, client may need to make changes to diet, depending upon 
how lupus has affected body such as clients with active lupus and fever may require more calories, when cholesterol or triglyceride levels become elevated, the client may be advised to eat a special diet, if client have swelling (edema) in feet or lower legs, decrease the amount of salt and sodium in diet. Also Extra vitamins are needed as vitamin $\mathrm{D}$ and calcium. Alfalfa and garlic are two foods should be avoided by people with lupus, because it contain an amino acid which can sending immune system into overdrive and flare up lupus symptoms [6,7].

Exercise; exercise interventions can improve aerobic fitness and reducing some SLE symptoms. SLE patients can safely engage in exercise training with physician clearance, but considerations should be taken for those (a) with cardiopulmonary involvement, (b) taking analgesics or corticosteroids, or (c) who experience ultraviolet light exposure [8].

Skin rash; Exposure to ultraviolet light, as from sunlight, can trigger or start skin rash, minimizing exposure to ultraviolet light by avoiding the sun, covering arms and legs, wearing a hat, and applying broad-spectrum sunscreen to protect skin,. Avoid going out when the sun's rays are the strongest. In most areas, this is between the hours of 10 a.m. and 4 p.m., especially during the summer [9].

Joint pain; joint pain is usually the first symptom of lupus. Taking care of joints when having joint or muscle problems, the first goal is to keep pain at a tolerable level through several ways as, apply heat or cold to the affected joints, support the affected joints with pillows, blankets, or splints (if ordered by doctor), rest the affected joints as much as possible and keep them elevated to reduce swelling. The second goal is to maintain joint function and increase muscle strength through the following techniques, take warm showers or baths to lessen stiffness, don't put any weight on an acutely inflamed joint, avoid strenuous activity and avoid any activity that causes increased pain, swelling, tenderness, or heat to the affected joint. Then, ask a physical therapist or trained family member to gently move the inflamed joint in all the directions. This will help prevent stiffness [10].

\subsection{Significance of Study}

Systemic lupus erythematosus (SLE) is associated with significant mortality, morbidity and cost for the individual patient and society. In the United States, African Americans (AAs) have 3-4 times greater prevalence of lupus, risk of developing lupus at an earlier age and lupus-related disease activity, organ damage and mortality compared with whites. Evidence-based self-care interventions that incorporate both social support and health education have reduced pain, improved function and delayed disability among patients with lupus [11].

Systemic Lupus Erythematosus is a complex disease to diagnose, treat and manage. In Egypt it was reported that; about 85cases monthly are admitted to the rheumatology department in Cairo University Hospital with different signs and symptoms [12].

\subsection{Aim of the Study}

The aim of this study is to evaluate the effect of health education based intervention on self-care among systemic lupus erythematosus clients.

\subsection{Hypothesis}

The following research hypothesis was formulated to achieve the aim of this study:

1- Studied clients' knowledge regarding systemic lupus erythematosus will be improved after health education based intervention compared to before intervention.

2- Studied clients' self-care practices will be improved after health education based intervention compared to before intervention.

3- There will be an improvement in studied clients' total Lupus Patient Reported Outcomes (Lupus PRO) after health education based intervention compared to before intervention.

\section{Subjects and Methods}

\subsection{Research Design}

A quasi-experimental design was used in this study

\subsection{Setting}

The study was conducted in Rheumatoloy Outpatients' clinic at Benha Teaching Hospital.

\subsection{Sample}

A Convenient sample of 60 systemic lupus erythematosus clients was recruited. The inclusion criteria were adult clients from both sex, didn't participate in any previous educational intervention regarding systemic lupus erythematosus and willing to participate in the study.

\subsection{Tool of Data Collection}

The researchers used three tools to collect data to achieve the aim of the study

Tool (1): An interview questionnaire, developed by the researchers based on literature review, and written in simple clear Arabic language consisted of two parts as the followings:

1st part: it was designed to collect data about demographic characteristics of SLE clients. It included questions about gender, age, educational qualification, marital status, and residence.

2nd part: it concerned with disease characteristics data such as; onset of the disease, other chronic diseases, family history of systemic lupus, and medical follow up.

Tool (2): Systemic Lupus Erythematosus Assessment Tool developed by the researchers and consisted of two parts as the followings:

1st part: SLE Knowledge Assessment tool, it was devoted to assess client's knowledge about SLE. It included close-ended questions. The questions covered areas such as, definition, causes, risk factors, signs and symptoms, diagnostic tests, treatment, and complications of systemic lupus. (pre- posttest format).

2.4.1. Scoring system for knowledge items: correct answered were predetermined according to literature 
review; a correct answer was scored one, and the incorrect answer was scored zero. These scores were summed-up and the total divided by the number of items giving mean score. These score were converted into a percent score, means and standard deviation were computed. The total knowledge was evaluated good $>75 \%$, average $50-75 \%$, and poor $<50 \%$.

2nd part: SLE Self Care Reported Practices Assessment Tool, it dealt with clients' practices about self-care. The self-care for SLE clients is composed of four items as, nutrition related practice, physical activities related practice, risks management related practice, and treatment and follow up related practice. (pre-posttest format).

2.4.2. Scoring system for clients self-care: Each question has 3 levels of answers: always, sometimes, and never. These were respectively scored 2,1 , and 0 . These scores were summed-up and the total divided by the number of items giving mean score. These score were converted into a percent score, means and standard deviation were computed. The total self-care was evaluated $<60 \%$ unsatisfactory, and $>60 \%$ satisfactory.

Tool (3): Lupus Patient Reported Outcomes: (Lupus PRO)

It was adapted from [13], to assess clients reported outcome. It has 43 items divided into 12 domains: (1) lupus symptoms (five items); (2) cognition (Two items); (3) lupus medication (Two items); (4) physical health (Two items); (5) pain-vitality (five items); (6) emotional health (five items); (7) procreation (six items); (8) body image (five items); (9) desires-goals (four items); (10) social support (two items); (11) coping(three items); and (12) satisfaction with care (four items). The Lupus PRO has 5 point Likert response format, where $0=$ None of the time/not applicable, $1=\mathrm{A}$ little of the time, $2=$ Some of the time, $3=$ Most of the time, $4=$ All of the time, $5=$ Not applicable (recode as 0 for scoring). The Lupus PRO was translated into Arabic. The subscale reliability point was correlated 0.89 .

Scoring system: Each item scored on Likert scale and each domain score was calculated by summing its items. A total score is calculated by summing the score of the 12 domains. Total Lupus PRO score presented in three categories as, low $>75 \%$, moderate $50-75 \%$, and high $<50 \%$.

\section{Validity and Reliability}

Content validity was done by five experts, three from the field of rheumatology medicine and two from community health nursing. The developed tool was reviewed for appropriateness of items and measuring the concepts. Modification was carried out accordingly. The reliability was done by Cronbach's Alpha coefficient test which revealed that the tool consisted of relatively homogenous items (0.82).

\subsection{Pilot Study}

The pilot study was carried out including six SLE clients chosen randomly from the same study setting to test content, clarity and consistency of the tools using the interviewing questionnaire as a pre-test sheet. Those who shared in the pilot study were excluded from the main study sample. Modifications were accordingly made on the study tools in order to be more applicable and the necessary changes were fulfilled by correction, omission or addition of items, until the final shape of the tools was reached.

\subsection{Fieldwork}

Data were collected throughout the period from beginning of March 2017 to end of July 2017. It was carried out by the researcher in the selected setting.

\subsection{Health Education Intervention Construction: Which Included 3 Phases}

\subsubsection{Preparation Phase}

Based on the results obtained from the interviewing and observational sheets, as well as literature review, the health educational intervention was developed by the researcher. It was implemented immediately after the pre-test.

Contents of intervention: Booklet was designed to meet clients' needs and to fit into their interest and levels of understanding. It consisted of different elements as follows: Introduction about disease process, manifestations, medication used and its side effect, complication of the disease, prevention of complication, and coping ability.

Methods of Teaching: All clients received the same intervention content using the same teaching methods, there were: Lectures/Discussions, and Presentation.

Media of Teaching: illustrated booklet.

\subsubsection{Implementation Phase}

The researcher visited the rheumatology outpatient clinic three times a week (Sundays, Tuesdays, and Thursdays) for five months from 9.00 a.m. to 12 mid-day. The total number of sessions was five sessions. During first session, the researchers met the client individually who fulfill the criteria, and explained the nature and aim of the study for a group of participants (6-8 participants). Oral consent was taken, and then asked each client to fill in the pretest using tool 1,2 , and 3 . This session took about 20-30 minutes.

During second, third, and forth sessions, the researchers started to explain information about introduction about disease process, manifestations, medication used and its side effect, and complication of the disease. Each session took about 30-45 minutes. The last session (5th session) contains information about coping ability. The researchers give posttest using tool ( 2 and 3 ), then provide them an illustrated booklet in order to help them at home.

Each session started by a summary about what had been given through the previous session then the objectives of the new topics, taking into consideration the use of simple language to suite the level of clients. Discussion, motivation and reinforcement during sessions were used to enhance learning. Direct reinforcement in the form of a copy of the content was given as a gift for each client to use it as future reference

\subsubsection{Evaluation Phase}

Evaluation of the intervention was done by using the posttest questionnaire which was the same format of 
pre-test in order to evaluate the effect of health education based intervention on self-care among clients with systemic lupus erythematosus, after implementation of the intervention.

\subsection{Administrative Design:}

Permission to conduct the study and implement the intervention was obtained by submission of official letters issued from Faculty of nursing, Benha University to the head of the Rheumatology Outpatients' clinic in Benha Teaching Hospital.

\subsection{Ethical Considerations}

Permission was obtained from each client before conducting the interview and after giving them a brief orientation to the purpose of the study, clients were reassured that their participation in the study is voluntary and about their right to withdraw at any time without giving reasons. They were also reassured that the information gathered would be confidential and used for the purpose of the study. No names were required on the forms to ensure anonymity and confidentiality.

\subsection{Statistical Analysis}

Data collected were analyzed using the Statistical Package for Social Sciences (SPSS), version 20. Mean, $\mathrm{SD}$, $\mathrm{T}$ test and correlation test were used to analyze the collected data. Statistical significance was considered at p-value $<0.05$.

\section{Results}

Table 1: shows that; $33.3 \%$ of studied clients aged from 30 to 34years old with mean age $28.76 \pm 5.98$, 90\% were female, $56.7 \%$ had secondary education, $73.3 \%$ of them were married and $60 \%$ of them were living in rural areas.

Table 1. Distribution of the studied subjects according to their demographic characteristics $(n=60)$.

\begin{tabular}{|l|c|c|}
\hline Demographic Characteristics & No. & \% \\
\hline Age in years & \multicolumn{2}{|c|}{} \\
$20-24$ & 13 & 21.7 \\
$25-30$ & 20 & 31.7 \\
$30-34$ & 8 & 33.3 \\
$35-40$ & \multicolumn{2}{|c|}{$\mathbf{2 8 . 7 6 \pm 5 . 9 8}$} \\
\hline Mean \pm SD & \multicolumn{2}{|c|}{} \\
\hline Gender & 6 & 13.3 \\
Male & 54, & 90 \\
Female & \multicolumn{2}{|c|}{} \\
\hline Educational qualification & 4 & 6.7 \\
Illiterate & 8 & 13.3 \\
Read and write & 34 & 56.7 \\
Secondary & 12 & 20.0 \\
Graduate & $2 \mathrm{~g}$, & 3.3 \\
Post graduate & \multicolumn{2}{|}{} \\
\hline Marital status & 44 & 73.3 \\
Married & 16, & 26.7 \\
Not married & 36 & 60.0 \\
\hline Residence & 24 & 40.0 \\
Rural & \multicolumn{2}{|c|}{} \\
Urban & \multicolumn{2}{|c|}{} \\
\hline
\end{tabular}

Table 2: illustrates that; $40 \%$ of studied clients had the disease from 1 to $<5$ years. $71.7 \%$ didn't have other chronic diseases. Moreover $36.7 \%$ of them had a family history of systemic lupus erythematous and $30 \%$ of them had follow up every six months.

Table 2. Distribution of the studied subjects regarding characteristics of SLE disease $(n=60)$.

\begin{tabular}{|l|c|c|}
\hline Disease Characteristics & No. & $\%$ \\
\hline Onset of the disease & 5 & 8.3 \\
< one year & 24 & 40.0 \\
$1-4$ & 13 & 21.7 \\
$5-10$ & 18 & 30.0 \\
More than 10 years & & \\
\hline Other chronic diseases & 17 & 28.3 \\
Yes & 43 & 71.7 \\
No & & \\
\hline Family history of & 22 & 36.7 \\
systemic lupus & 38 & 63.3 \\
Yes & & \\
No & 8 & 13.3 \\
\hline Medical follow up & 10 & 16.7 \\
Monthly & 14 & 23.3 \\
Every two months & 18 & 30.0 \\
Every three months & 10, & 16.7 \\
Every six months & & \\
Irregular follow up & & \\
\hline
\end{tabular}

Table 3: illustrates that, there was statistically significant differences in total knowledge between pre and post intervention.

Figure 1: displays that, before the intervention; $55 \%$ of the studied clients had poor total knowledge, $45 \%$ had average total knowledge and $0 \%$ had good total knowledge scores regarding systemic lupus erythematous disease, while after the intervention; good total knowledge scores increased to $95 \%$ and average total knowledge decreased to $5 \%$..

Table 4: shows that; all self-care reported practices items of studied subjects were improved significantly at post intervention phase with highly statistical significant differences between pre and post intervention ( $\mathrm{P}<0.001)$.

Figure 2. displays that, before the intervention; $18.3 \%$ of studied clients had satisfactory total self-care reported practices, which increased after the intervention to $83.3 \%$.

Table 5: shows that; mean total Lupus PRO score of studied clients were improved significantly post intervention $159.4200 \pm 6.30546$ compared by $90.1400 \pm 5.75347$ pre intervention. There were highly statistical significant differences regarding all Lupus PRO items between pre and post intervention.

Figure 3. displays that, pre the intervention phase; $83.3 \%$ of the studied clients had low total Lupus PRO score, 16.7\% had moderate total Lupus PRO score and 0\% had high total Lupus PRO score, while post the intervention; high total Lupus PRO score increased to $35 \%$ and moderate total Lupus PRO score increased to 65\%.

Table 6: illustrates that; There was a positive association among studied subjects knowledge and selfcare scores at the pre-intervention phase, while on the other hand there was a negative association between their self-care practice and their Lupus PRO score.in addition there was a highly positive association among studied subjects total knowledge, self-care practice and total Lupus PRO score at the post intervention phase. 
Table 3. Mean knowledge scores of the studied clients regarding systemic lupus erythematous disease pre and post intervention ( $\mathrm{n}=60)$.

\begin{tabular}{|l|c|c|c|c|c|}
\hline \multirow{2}{*}{ Knowledge } & \multirow{2}{*}{ Score } & Pre-intervention & Post-intervention & \multirow{2}{*}{ Paired t test } & \multirow{2}{*}{ P value } \\
\cline { 3 - 4 } & & Mean \pm SD & Mean \pm SD & & \\
\hline Definition of systemic lupus & 1 & $.6500 \pm .48099$ & $.8500 \pm .36008$ & -2.352 & $<0.05^{*}$ \\
\hline Causes of systemic lupus & 1 & $.4333 \pm .49972$ & $.8500 \pm .36008$ & -5.217 & $<0.001^{* *}$ \\
\hline Risk factors of systemic lupus & 2 & $.5500 \pm .50169$ & $1.6667 \pm .47538$ & -14.106 & $<0.001^{* *}$ \\
\hline Signs and symptoms of systemic lupus & 7 & $2.9167 \pm 1.38137$ & $5.9333 \pm .77824$ & -13.726 & $<0.001^{* *}$ \\
\hline Diagnostic tests of systemic lupus & 4 & $1.9500 \pm .69927$ & $3.7333 \pm .44595$ & -17.171 & $<0.001^{* *}$ \\
\hline Treatment of systemic lupus & 4 & $2.2667 \pm .73338$ & $3.8167 \pm .39020$ & -15.192 & $<0.001^{* *}$ \\
\hline Complications of systemic lupus & 11 & $5.8333 \pm 1.32980$ & $10.0000 \pm .86358$ & -18.776 & $<0.001^{* *}$ \\
\hline Total knowledge & 30 & $14.6000 \pm 2.38071$ & $26.8500 \pm 1.77387$ & -33.790 & $<0.001^{* *}$ \\
\hline
\end{tabular}

* Statistically significant difference $(p \leqslant 0.05), * *$ Highly statistically significant difference $(p \leqslant 0.001)$.

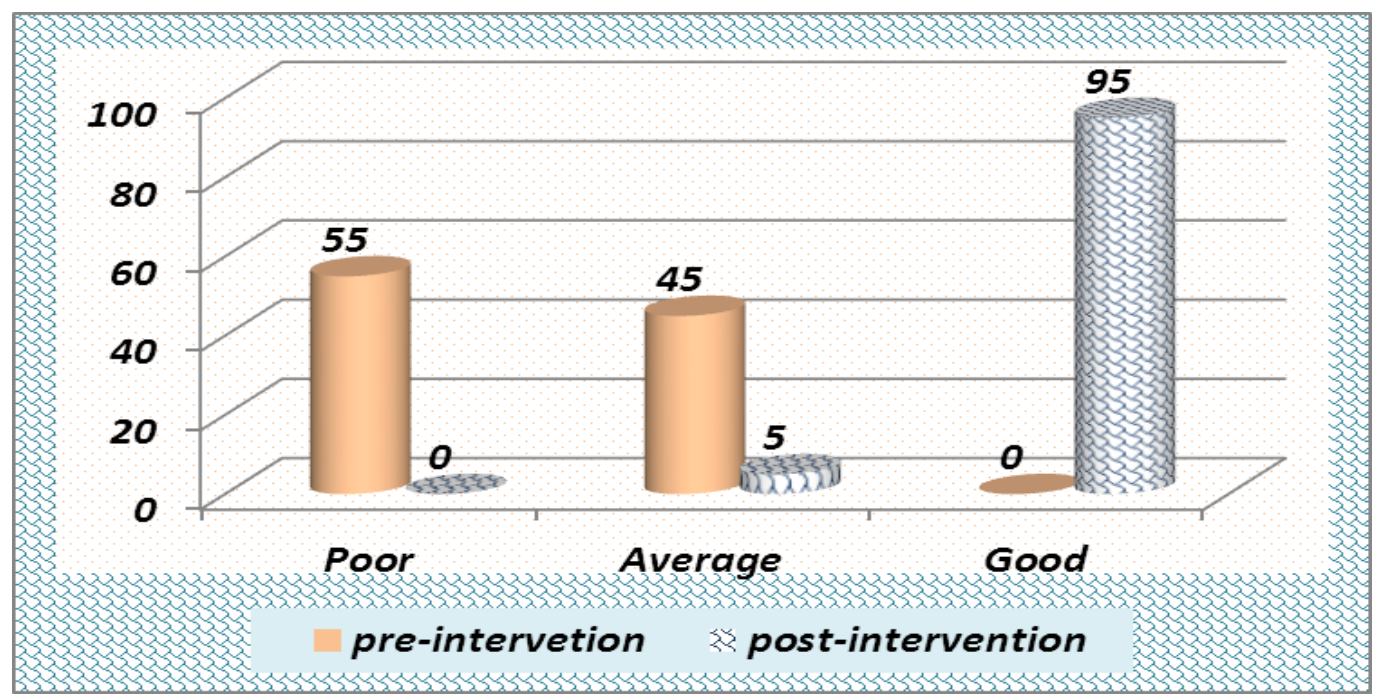

Figure 1. Distribution of studied clients regarding to their total knowledge score about systemic lupus erythematous disease pre and post intervention $(\mathrm{n}=60)$

Table 4. Mean self-care reported practices scores of studied clients pre and post intervention $(n=60)$

\begin{tabular}{|l|c|c|c|c|c|}
\hline \multirow{2}{*}{ Self-care reported practices } & \multirow{2}{*}{ Score } & Pre-intervention & Post-intervention & \multirow{2}{*}{ Paired t test } & \multirow{2}{*}{ P value } \\
\cline { 3 - 4 } & & Mean \pm SD & Mean \pm SD & & \\
\hline Nutrition related practice & 8 & $3.9400 \pm .89008$ & $5.9000 \pm 1.58114$ & -6.572 & $<0.001^{* *}$ \\
\hline Physical activities related practice & 12 & $5.3600 \pm .72168$ & $9.8800 \pm 2.53659$ & -11.070 & $<0.001^{* *}$ \\
\hline Risks management related practice & 9 & $4.3600 \pm 1.72331$ & $7.3200 \pm .93547$ & -13.057 & $<0.001^{* *}$ \\
\hline Treatment and follow up related practice & 7 & $3.3400 \pm .51942$ & $5.2600 \pm 1.04608$ & -14.061 & $<0.001^{* *}$ \\
\hline Total self-care related practice & 36 & $17.0000 \pm 2.19461$ & $28.3600 \pm 4.98471$ & -15.844 & $<0.001^{* *}$ \\
\hline
\end{tabular}

* Statistically significant difference $(\mathrm{p} \leqslant 0.05)$, **Highly statistically significant difference $(\mathrm{p} \leqslant 0.001)$.

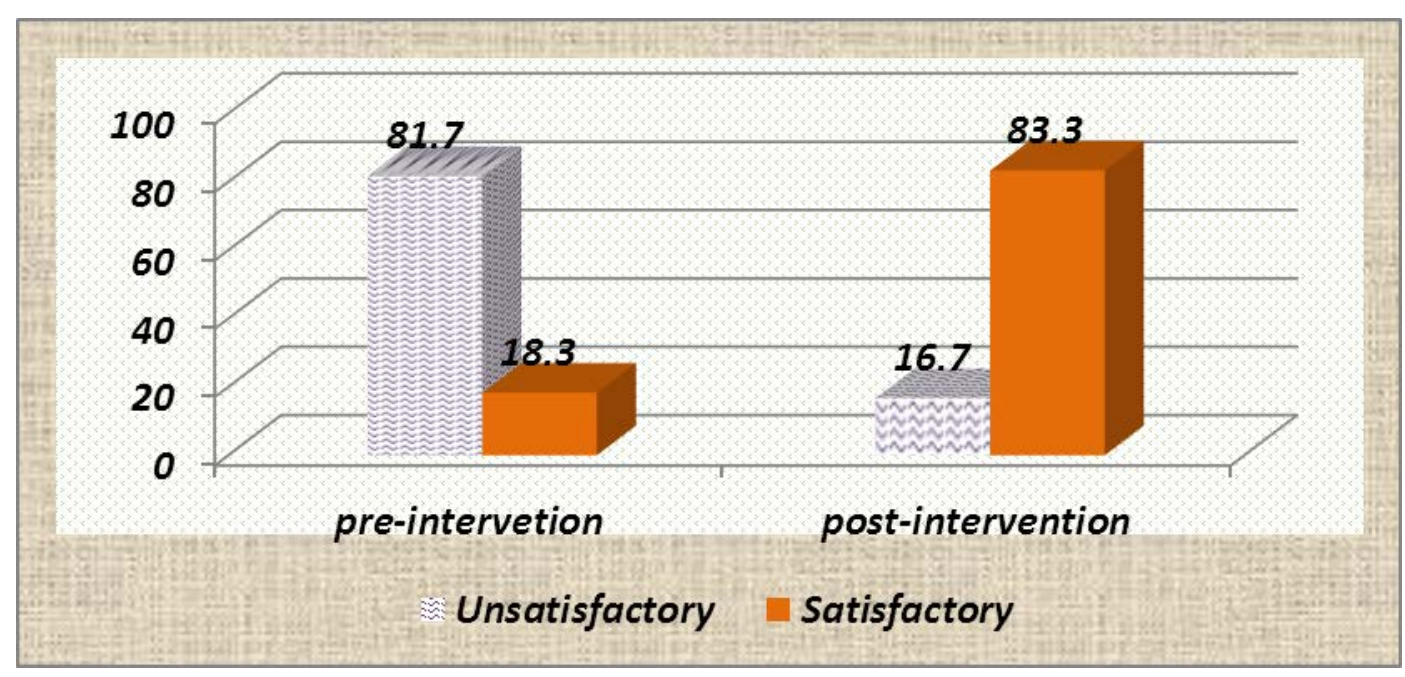

Figure 2. Distribution of the studied clients regarding to their total self-care reported practices score levels pre and post intervention $(n=60)$. 
Table 5. Mean Lupus PRO scores of studied clients pre and post intervention $(n=60)$

\begin{tabular}{|c|c|c|c|c|c|}
\hline \multirow{2}{*}{ Lupus PRO } & \multirow{2}{*}{ Score } & Pre-intervention & Post-intervention & \multirow{2}{*}{ Paired t test } & \multirow{2}{*}{$\mathrm{P}$ value } \\
\hline & & Mean \pm SD & & & \\
\hline Lupus Symptoms & 15 & $7.3800 \pm 1.73664$ & $9.9400 \pm 1.57026$ & -7.568 & $<0.001^{* *}$ \\
\hline Cognition & 10 & $3.5800 \pm 1.56609$ & $6.4000 \pm 1.42857$ & -7.468 & $<0.001^{* *}$ \\
\hline Lupus Medication & 10 & $3.7000 \pm 1.56818$ & $7.5400 \pm 1.19881$ & -12.406 & $<0.001^{* *}$ \\
\hline Physical Health & 10 & $3.5000 \pm 1.07381$ & $7.3600 \pm .98478$ & -17.587 & $<0.001^{* *}$ \\
\hline Pain-Vitality & 25 & $12.1200 \pm 1.28793$ & $19.3400 \pm 1.49298$ & -22.851 & $<0.001^{* *}$ \\
\hline Emotional Health & 25 & $9.6200 \pm 1.78303$ & $18.0000 \pm 2.16654$ & -21.173 & $<0.001^{* *}$ \\
\hline Procreation & 30 & $11.8000 \pm 1.44279$ & $22.6600 \pm 1.81389$ & -33.861 & $<0.001^{* *}$ \\
\hline Body Image & 25 & $10.3400 \pm 1.69766$ & $18.8800 \pm 1.36487$ & -25.065 & $<0.001^{* *}$ \\
\hline Desires-Goals & 20 & $8.3800 \pm 1.12286$ & $14.2200 \pm 2.28830$ & -16.781 & $<0.001^{* *}$ \\
\hline Social support & 10 & $5.0600 \pm 1.44857$ & $6.8800 \pm 1.09991$ & -8.387 & $<0.001 * *$ \\
\hline Coping & 15 & $6.2600 \pm 2.30182$ & $10.9800 \pm 1.31692$ & -11.594 & $<0.001^{* *}$ \\
\hline Satisfaction with care & 20 & $8.4000 \pm 2.36471$ & $17.2200 \pm 2.44357$ & -16.899 & $<0.001^{* *}$ \\
\hline Total Lupus PRO score & 215 & $90.1400 \pm 5.75347$ & $159.4200 \pm 6.30546$ & -62.880 & $<0.001^{* *}$ \\
\hline
\end{tabular}

* Statistically significant difference $(\mathrm{p} \leqslant 0.05),{ }^{* *}$ Highly statistically significant difference $(\mathrm{p} \leqslant 0.001)$.

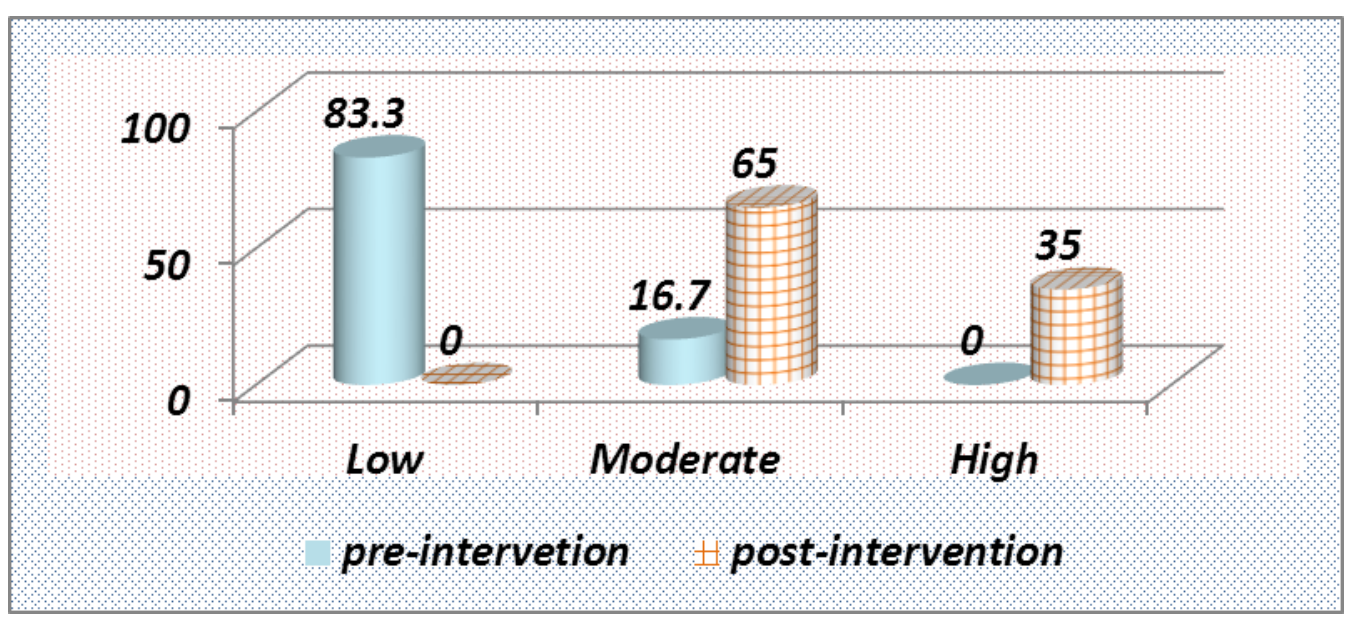

Figure 3. Distribution of the studied clients regarding to their total Lupus PRO score levels pre and post intervention ( $\mathrm{n}=60$ ).

Table 6. Correlation between studied clients' total Lupus PRO score, total knowledge score and total self-care reported practices score pre/post intervention

\begin{tabular}{|c|c|c|c|c|c|c|c|}
\hline \multirow{2}{*}{\multicolumn{2}{|c|}{ Variables }} & \multicolumn{3}{|c|}{ Pre-intervention } & \multicolumn{3}{|c|}{ Post-intervention } \\
\hline & & \multirow{2}{*}{$\begin{array}{c}\text { Knowledge } \\
1 \\
\end{array}$} & \multirow{2}{*}{$\begin{array}{c}\text { Self-care practice } \\
.188\end{array}$} & \multirow{2}{*}{$\begin{array}{c}\text { Lupus PRO } \\
.253\end{array}$} & \multirow{2}{*}{$\begin{array}{c}\text { Knowledge } \\
-\end{array}$} & \multirow{2}{*}{$\begin{array}{c}\text { Self-care practice } \\
-\end{array}$} & \multirow{2}{*}{$\begin{array}{c}\text { Lupus PRO } \\
-\end{array}$} \\
\hline Knoulodro nu intoryontion & $\mathrm{R}$ & & & & & & \\
\hline Knowledge pre intervention & $\mathrm{p}$-value & & .151 & .051 & - & - & - \\
\hline \multirow{2}{*}{$\begin{array}{l}\text { Self-care reported practice } \\
\text { pre-intervention }\end{array}$} & $\mathrm{R}$ & .188 & 1 & -.042 & - & - & - \\
\hline & $\mathrm{p}$-value & .151 & & .750 & - & - & - \\
\hline \multirow{2}{*}{ Lupus PRO pre intervention } & $\mathrm{R}$ & .253 & -.042 & 1 & - & - & - \\
\hline & $\mathrm{p}$-value & .051 & .750 & & - & - & - \\
\hline \multirow{2}{*}{ Knowledge post-intervention } & $\mathrm{R}$ & - & - & - & 1 & $.556^{* *}$ & $.476^{* *}$ \\
\hline & $\mathrm{p}$-value & - & - & - & & .000 & .000 \\
\hline \multirow{2}{*}{$\begin{array}{l}\text { Self care reported practice } \\
\text { post-intervention }\end{array}$} & $\mathrm{R}$ & - & - & - & $.556^{* *}$ & 1 & .184 \\
\hline & p-value & - & - & - & .000 & & .160 \\
\hline \multirow{2}{*}{$\begin{array}{l}\text { Lupus PRO } \\
\text { post-intervention }\end{array}$} & $\mathrm{R}$ & - & - & - & $.476^{* *}$ & .184 & 1 \\
\hline & p-value & - & - & - & .000 & .160 & \\
\hline
\end{tabular}

\section{Discussion}

Systemic lupus erythematosus (SLE) is an episodic, multisystem, autoimmune disease characterized by widespread inflammation of blood vessels and connective tissue. There is no cure for lupus, but medical interventions and lifestyle changes can help control it. The seriousness of SLE can range from mild to life-threatening. Clients with lupus who get proper medical care, preventive care, and education can significantly improve function and quality of life [14].

This study aimed to evaluate the effect of health education based intervention on self-care among systemic lupus erythematosus clients.

According to demographic characteristics of the studied sample, the present study results showed that, the mean age of studied sample was 28.76 \pm 5.98 , had different levels of education with dominance of secondary education. This 
finding was in accordance with [5] who stated that SLE affects young adults and starts in the second or third decade of life. Also, [15], who found that mean age was $27.57 \pm 8.95$, and $(52.6 \%)$ had mid-level education or higher. The current study illustrates that most of clients were female, less than three quarters were married. These findings were consistent with [16], who found that all participants were female and the majority were married. Also [17] reported that SLE female to male ratio was 9:1.similar to [18] who reported that, the majority of studied sample were female.

Regarding history of systemic lupus erythematous, the present study revealed that less than three quarters of clients didn't have other chronic diseases, less than two thirds didn't have a family history of systemic lupus erythematous. Congruent with study result, [19] reported that a family history of SLE was significantly more common in juvenile-onset SLE than in adult-onset disease, about 36\% of juvenile-onset SLE patients have a positive family history of SLE as opposed to $12 \%$ of adult-onset disease patients $(\mathrm{p}=0.011)$. Also other autoimmune conditions such as rheumatoid arthritis, hypothyroidism did not differ significantly between the two groups.

As regards to the onset of disease. The present study findings showed that around less than half of clients with SLE had ranged from less than one year to less than five year. This result on line with [17] who stated that the onset of disease among participants was from 1-5 years.

Concerning clients knowledge about SLE, there were deficient in knowledge before carrying out the intervention, this may be due to unavailability of educational programs to give clients required information about disease. After implementation of the intervention, there were improving mean and standard deviation of studied clients' knowledge regarding systemic lupus erythematous disease post intervention with statistically significant differences between pre and post intervention. This result confirms the hypothesis one in this study. This study finding was supported by [20] mentioned that, the continuous care model significantly improved patients' knowledge level and awareness of their disease. In this respect [12] added that more than two thirds of the patients included in their study were had satisfactory awareness level regarding SLE post-implementation of self-management guidelines with highly statistical significance.

As regards mean Lupus PRO scores of studied clients, the present study results illustrated highly statistical significant improvement regarding all Lupus PRO items post intervention. This could reflected the importance of health education interventions and programs in improving health outcome for SLE clients. This finding was in accordance with [21], who found that the success of an intervention can be measured by improvements in ability to perform daily living activities, maintain a healthy diet, and exercise regularly as outcome measures. As well [11] clarified that self-management interventions that incorporate both social support and health education had a positive effect in improving health outcome through reduced pain, improved function and delayed disability among patients with lupus.

The results of the current study indicated highly positive association among studied subjects total knowledge, self-care practice and total Lupus PRO score post intervention. This result was in agreement with [21], who stressed that empowerment through health education and active involvement of members of the community affected by systemic lupus erythematosus in related interventions is integral to health improvement. While in contrast with [22] who found that self care practices were uncorrelated with health related quality of life and health outcomes in lupus patients.

\section{Conclusion}

According to results this study concluded that: the health education based intervention had a significant effect on the improvement of SLE clients' knowledge and self-care practices. The Lupus PRO of studied clients were improved significantly post intervention. There was a highly positive association among studied subjects total knowledge, self-care practice and total Lupus PRO score at the post intervention phase.

\section{Recommendations}

- Patient education is an important part of standard care; establishing patient education program to improve SLE clients care by written instructions must be available in all rheumatology clinics.

- Replicate this study for large number of clients and in different setting.

- Future research is proposed to explore the effect of self-care intervention on controlling SLE symptoms. (outcome).

\section{References}

[1] Centers for Disease Control and Prevention, (2018). Lupus Detailed Fact Sheet Available from https://www.cdc.gov/lupus/facts/detailed.html Accessed on 15/6/2017.

[2] WebMD, (2018). Lupus (Systemic Lupus Erythematosus) - Cause Available form: https://www.webmd.com/lupus/tc/lupus-systemiclupus-erythematosus-cause Accessed on 15/6/2017.

[3] Parrondo, R. (2011). Integral treatment of systemic lupus erythematosus, challenges in rheumatology, Available from: https://www.intechopen.com/books/challenges-in-rheumatology /integral-treatment-of-systemic-lupus-erythematosus, Accessed on 4/2/2017.

[4] Petri, M. (2018). Life-Threatening Complications of Systemic Lupus Erythematosus. Available from:

file://D:/Research/systemic\%20lupus/9780857293572-c1.pdf Accessed on 20/6/2017.

[5] Jonkman, M. (2016). Autoimmune Bullous Diseases(Text and Review). 1st ed., Springer International Publishing, Swizerland, P.152.

[6] The National Resource Center on Lupus, (2018). Diet and nutrition with lupus. Available from: https://resources.lupus.org/entry/diet-or-nutrition-plan. Accessed on $3 / 7 / 2017$.

[7] Johns Hopkins Lupus Center, (2018). Things to Avoid. Available from: https://www.hopkinslupus.org/lupus-info/lifestyle-additionalinformation/avoid/ Accessed on 3/7/2017

[8] Elizabeth, Y., and James, B. (2016). Exercise Benefits and Considerations for Individuals with Systemic Lupus Erythematosus. Strength \& Conditioning Journal: 38(6); Pp. 69-75. 
[9] Kuhn A., Gensch K., Haust M., Meuth AM., Boyer F., Dupuy P, Lehmann P., Metze D, Ruzicka T. (2011). Photoprotective effects of a broad-spectrum sunscreen in ultraviolet-induced cutaneous lupus erythematosus: A randomized, vehicle-controlled, doubleblind study. J Am Acad Dermatol.:64(1); Pp.37-48.

[10] National Institute of Arthritis and Musculoskeletal and Skin Diseases, (2006). Lupus A Patient Care Guide for Nurses and Other Health Professionals, 3rd ed. Available from http://www.aaaceus.com/courses/NL0210_article1.pdf.

[11] Williams, E., Egede, L., Faith, T., and Oates, J. (2017). Effective Self-Management Interventions for Patients With Lupus: Potential Impact of Peer Mentoring, The American Journal of the Medical sciences; 353(6): Pp. 580-592.

[12] Mostafa, H., and Abd-Elrehem, T. (2017). Self- Management Guidelines: Effect on Awareness of Patients with Systemic Lupus Erythmatosus, Egypt, IOSR Journal of Nursing and Health Science; 6(6): Pp. 15-23.

[13] Jolly, M. and Pickard, S. (2012). Lupus PRO (Lupus Patient Reported Outcome Tool) v1.7, Available@http://lupuspro.com/files/45490367.pdf, Accessed on January 2017.

[14] Brown, R., Shaftman, S., Tilley, B., Anthony, K., Kral, M., Maxson, B., and Nietert, P. (2012). The health education for lupus patients study: A randomized controlled cognitivebehavioral intervention targeting psychosocial adjustment and quality of life in adolescent females with systemic lupus erythematosus. American Journal of Medical Science,; 344(4): Pp.274-282.

[15] Reis, M. \&Costa, I. (2010). Health-related quality of life in patients with systemic lupus erythematosus in Midwest Brazil. Bras J Rheumatol 2010; 50(4): 408-22.

[16] O’Riordan, R. Doran, M. and Connolly, D. (2017). Fatigue and Activity Management Education for Individuals with Systemic Lupus Erythematosus. Hindawi. Occupational Therapy International, Volume 2017, Article ID 4530104, 11 pages.

[17] Macejová, Z., Záriková, M., and Oetterová, M. (2013). SYSTEMIC LUPUS ERYTHEMATOSUS - DISEASE IMPACT
ON PATIENTS, Slovakia, Cent Eur J Public Health; 21 (3): Pp. 171-173.

[18] El Hadidi KT., Medhat BM., Abdel Baki NM., Abdel Kafy ., Abdelrahaman W., Yousri AY., et al., (2018). Characteristics of systemic lupus erythematosus in a sample of the Egyptian population: a retrospective cohort of 1109 patients from a single center, Lupus Journal; (2018) 0: Pp. 1-9.

[19] Durrani, M., Sangle, S., Jordan , N., and Cruz, D. (2013). A Comparative Study For High Prevalence of A Positive Family History of Systemic Lupus Erythematosus In Juvenile-Onset Systemic Lupus Erythematosus Versus Adult-Onset Disease. American College oF Rheumatology. Available @ http://acrabstracts.org/abstract/a-comparative-study-for-highprevalence-of-a-positive-family-history-of-systemic-lupuserythematosus-in-juvenile-onset-systemic-lupus-erythematosusversus-adult-onset-disease/.

[20] Sahebalzamani, M ., Farahani, H., Jamarani, T., Faezi, T., Moradi, K. and Paragomi, P. (2017). Effects of a Continuous Care Model on Patients' Knowledge and Health-Related Quality of Life in Systemic Lupus Erythematosus. Rehabil Nurs.:42(6); E9-E18.

[21] Feldman, CH., Bermas, BL., Zibit, M., Fraser, P., Todd, DJ., Fortin, PR., Massarotti, E., and Costenbader, KH. (2013). Designing an intervention for women with systemic lupus erythematosus from medically underserved areas to improve care: a qualitative study, Canada, Lupus; (2013) 22: Pp. 52-62.

[22] Sari, N. (2016). SYSTEMIC LUPUS ERYTHEMATOSUS: Correlation between Sensory Knowledge, Self-Efficacy, Preventive Action towards Triggers Factors, Self-Care Practice and Quality of Life, Available@ http://eprints.ners.unair.ac.id/269/3/SYSTEMIC\%20LUPUS\%20E RYTHEMATOSUS\%20CORRELATION\%20BETWEEN\%20SE NSORY\%20KNOWLEDGE\%2C\%20SELFEFFICACY\%2C\%20 PREVENTIVE\%20ACTION\%20TOWARDS\%20TRIGGER\%20 FACTORS\%2C\%20SELFCARE\%20PRACTICE\%20AND\%20Q UALITY\%20OF\%20LIFE.pdf, Accessed on December 2017. 